\title{
CONFIANÇA COMO FATOR DE REDUÇÃO DA VULNERABILIDADE HUMANA NO AMBIENTE DE TRABALHO
}

\section{RESUMO}

0 ambiente de trabalho predominante atual mente nas organizações complexas pode tanto atuar em favor da maior produtividade quanto debilitar a coesão e os laços de cooperação no trabal ho. N este último caso, faz emergir nos profissionais das empresas uma sensação de vulnerabilidade, traduzida por relacionamentos mais efêmeros e superficiais, que arrefecem a ação das pessoas. N este artigo, trabalhou- se com a premissa de que o estabelecimento de um ambiente de confiança pode neutralizar essa sensação. 0 estudo teve como fim investigar se os profissionais percebem fragilidade nas relações de trabalho, como reagem à situação, e quais suas influências no processo de gestão. 0 material discursivo, recolhido de entrevistas em profundidade com gerentes de organizações multinacionais e nacionais de grande e médio porte, traz explicações para os motivos que levam à instalação da sensação de vulnerabilidade no trabalho. Essas reflexões permitem inferir que é possível instalar procedimentos de gestão, padrões de comportamento e cultura organizacional que atuem na reversão desse estado de coisas e desenvolvam ambientes de trabalho mais propícios.

\section{Rosa Maria Fischer \\ FEAUSP}

\section{José Gaspar Nayme Novelli}

IBMEC - BRASÍபA

\begin{abstract}
T he currently predominant working environment in complex organizations may either operate in favor of enhanced productivity or weaken the cohesion and ties of cooper ation in the workplace. In the latter case it causes professionals to experiencea feeling of vulnerability, which translates into more ephemeral and superficial relationships that have the effect of moderating people's actions. This article worked with the assumption that establishing an atmosphere of trust may neutralize this feeling. The purpose of the study was to investigate if professionals perceive any fragility in their working relations, how they react to the situation and how it influences the management process. The material collected from in-depth interviews with managers of major and medium-size multinational and national organizations provides explanations for the reasons that lead to the installation of a feeling of vulnerability at work. These reflections allow us to infer that it is possible to install management procedures, behavior standards and an organizational culture that operate to rever se this state of affairs and to develop a favorable working environment.
\end{abstract}

PALAVRAS-CHAVE Trabalho, confiança, coesão, vulnerabilidade, relacionamentos.

KEMWORDWork, trust, cohesion, vulnerability, relationships. 


\section{INTRODUÇÃO}

0 inconformismo do economista e pensador Robert Kurz (1992) sobre o rumo dos eventos no mundo atual oferece uma base para a compreensão de certo incômodo presente nos relacionamentos humanos. Afirma 0 autor que $o$ homem do século XXI é um ser que se valoriza ininterruptamente, pensa esonha economicamente de forma contínua econsidera todas as relações, até pessoais eíntimas, como relações de freguesia.

De forma subjacente, nesta reflexão encontra-se retratado o dilema entre considerar hoje os relacionamentos como questão de mera obrigação formal, uma espécie de abnegação necessária ao alcance de objetivos de natureza econômica, e, de outra parte, considerar a natureza humana socialmente orientada para concretizar, com sucesso, suas realizações. Bauman (2003, p. 6) descortina esse dilema quando assinala que 0 indivíduo "[...] precisa dos outros como do ar que respira, mas, ao mesmo tempo, ele tem medo de desenvolver relacionamentos mais profundos, que o imobilizem num mundo em permanente movimento". Em outras palavras, o excesso de movimento pode servir de instrumento à paralisia dos relacionamentos sociais.

Sennett (1988, p. 399) aponta os riscos e os percal ços do "esvaziamento dos vínculos de associação e de compromisso mútuo entre as pessoas". Isso é tratado não só por ele como por vários autores que refletiram acerca da chamada pós-modernidade como uma das características mais determinantes da fragilização dos valores sociais e da sociabilidade na sociedade contemporânea. Fazendo um corte epistemológico para empregar sua análise no contexto do mundo do trabalho, o autor observa que as habilidades multifuncionais do trabal hador moderno dotam o processo produtivo de mais flexibilidade para ter mais capacidade de adaptação ao ambiente externo. Tal flexibilidade, porém, restringe a capacidade de formação delaços de identidade entre grupos, pois os relacionamentos não se dão mais entre pares que comungam a mesma especial ização. N essa medida, o trabal ho, que estabel ecia fortes vínculos pessoais e grupais em um passado ainda relativamente próximo, deixa de ser 0 elo entre as pessoas e destas com a organização onde exercem sua profissão.

$\mathrm{N}$ a década de 1980, mudanças de amplo espectro e radical profundidade nas arenas econômica, social e interpessoal surpreenderam todo o mundo, principalmente aquel e del imitado pel as rel ações econômicas de produção capital ista de bens e serviços. Das principais rupturas no modelo de gestão, destacam-se a maior abertura das empresas para a absorção de transformações provenientes do ambiente externo e a criação de estruturas organizacionais aptas a oferecer respostas rápidas e objetivas para os clientes. Com relação a esse aspecto, DiM aggio (2001, p. 210, tradução nossa) destaca, como consenso entre os autores que estudam mudanças organizacionais, " [...] 0 achatamento de estruturas hierárquicas, o investimento nos trabal hos em equipe e o menor detal hamento das descrições de cargo". Porém, à medida que os indicadores de produtividade alcançam padrões de desempenho inéditos, com o apoio de técnicas flexíveis de trabal ho, o estímulo à busca de satisfação de interesses particulares age em sentido contrário ao trabal ho mais cooperativo.

Esta pesquisa procurou conhecer as percepções de gerentes de organizações empresariais acerca da relação entre $o$ sentimento de vulnerabilidade e a presença ou ausência de um ambiente de confiança, principal mente a partir das transformações que alteraram o processo e as relações de trabal ho nos últimos anos. São apresentados os resultados do levantamento e da análise de opiniões e percepções obtidas junto a uma amostra de respondentes acerca da associação en tre vul nerabilidade e confiança no ambiente de trabalho.

0 texto foi elaborado com a seguinte estrutura: síntese da fundamentação teórica com ênfase no debate acerca do conceito de confiança; descrição da metodologia empregada; e discussão analítica dos dados levantados no discurso dos entrevistados.

\section{FUNDAMENTAÇÃO TEÓRICA}

Conforme estudos elaborados em 2000 e 2001 pelo Dieese, as al terações do contexto de organização do trabalho elevaram, no Brasil, a produtividade em 2,55\% entre $1992 \mathrm{e}$ 1998, em 40 setores econômicos, dentre os quais se destacam áreas importantes da economia, como o agronegócio (4\%), a indústria têxtil (5,3\%), a indústria automotiva $(9,6 \%)$ e a siderurgia ( $10,3 \%)$.

No mesmo período, $17 \%$ das pessoas empregadas passaram à condição de não-empregadas e, mesmo entre os ocupados, $16,4 \%$ começaram a trabalhar sem carteira assinada, o que explica a constatação de que $73,1 \%$ das pessoas que entendiam ser "mais bem pagas" no início da década de 1990 consideraram-se em condições inferiores no final dela, ou seja, passaram a ter uma percepção da precarização do valor de seu trabalho (IBGE, 2003).

Entre os trabal hadores, disseminou-se a noção de que podem ocorrer rupturas na relação de trabalho independentemente do desempenho profissional, gerando malestar e ansiedade expressos por manifestações de descon- 
tentamento (BURBACH e outros, 1998). Esses sintomas são mais evidentes quando a economia está em crise, com efeitos negativos perceptíveis na lucratividade das empresas, as quais geralmente optam por reduzir custos mediante cortes de mão-de-obra empregada. Quando as condições se invertem e o desenvolvimento econômico se mostra vigoroso, são os empregados que buscam meIhores oportunidades, livres de qualquer acordo previamente firmado com a empresa e conscientes de que são os únicos responsáveis por seu sucesso profissional e segurança financeira.

Como nas últimas décadas o Brasil vem experimentando períodos espasmódicos de crescimento econômico, o trabal hador tornou-se sistematicamente o elo mais frágil nessa cadeia, sofrendo amiúde com tais rupturas. Informações do IBGE indicam que a maioria dos brasileiros não usufrui os direitos sociais previstos em lei: não têm direito a 130 salário ( $54 \%$ ), férias remuneradas (55\%) ou plano de saúde (81\%). 56\% ganham no máximo dois salários mínimos, $11 \%$ estão desempregados e 16\% fazem "bicos", conforme consta no caderno "O País dos Direitos de Papel", publicado no diário Folha de S. Paulo (2002).

Esse contexto indica que as organizações brasileiras não estão investindo em um dos el ementos apontados pela moderna literatura de gestão de pessoas como essencial para ganharem eficiência: a constituição, consolidação e emprego permanente de equipes caracterizadas pela coesão interna e boa integração de seus componentes. Às vezes de forma abrupta, em face de inesperada crise econômico-financeira; outras vezes de forma gradual, em um lento processo de deterioração das relações de trabaIho, 0 ambiente organizacional tende a ser infértil para o estabel ecimento da confiança que sedimenta a existência desses grupos e equipes.

A coesão é el emento-chave para o estabelecimento de redes internas que compartilhem expertises, competências e melhores práticas (LIMERICK, CUNNINGTON, 1994). 0 principal pilar sobre o qual a coesão se sustenta éa existência de confiança entre os membros do grupo. A existência de atributos de confiança, dentre outros aspectos, abranda a necessidade de formal ização de contratose reduz ou elimina controles hierárquicos (DAVIS e outros, 2000) , contribuindo para a redução de custos de transação no interior das empresas.

As relações de confiança expressam desafios no mínimo entre duas partes: confiado e confiante. Da parte do confiante, a decisão é quase sempre problemática: decidir se investe ou não confiança no potencial realizador do confiado; da parte do confiado, decidir se mantém o trato ou o quebra, principalmente quando a decisão por uma ou outra opção o beneficia (COLEM AN, 1990).

\section{Conceito de confiança}

N os estudos em Economia, ressaltam-se análises acerca da confiança concebida como um elemento que permite estimar ganhos e perdas nas relações de troca. No campo da psicologia, evidenciam-se os atributos existentes no papel de confiado e confiante nas relações interpessoais. $\mathrm{N}$ a Sociologia, a confiança é considerada propriedade incorporada nas relações sociais, dando-Ihes consistência e perenidade.

Rousseau e outros (1998) assinalam que, quando o foco de interesse se concentra em resultados econômicos, os pesquisadores, em geral, conceituam confiança como causa potencial na escolha de algum cenário segundo experiências anteriores. A visão puramente sociológica considera a confiança como resultado de arranjos institucional mente estabel ecidos. Já numa visão psicossocial, a confiança se manifesta como elemento moderador de relacionamentos, na relação pessoa com pessoa, até em relações mais complexas, envolvendo, por exemplo, várias organizações. Chama-se a essa confiança de relacional, por derivar de interações repetidas no tempo e no espaço entre confiado e confiante.

Desenhou-se o escopo conceitual de confiança para este trabalho adotando esse último enfoque, que permite realçar as particularidades da gestão organizacional, campo de estudo da administração. Tal enfoque possibilita analisar o construto em manifestações concretas, tomando o espaço das organizações complexas como campo empírico para pesquisa.

Na pesquisa realizada, foi necessário fazer um corte epistemológico que propiciasse trabal har com a noção de confiança, evitando que a amplitude do conceito impedisse sua operacionalização para efeito de levantamento e análise das percepções das pessoas. Optou-se por realizar o corte focando como e o que as pessoas expressam acerca das relações interpessoais prevalentes no âmbito organizacional em que se dedicam ao trabalho. 0 pressuposto adotado é que interações no ambiente de trabaIho se moldam em redes de relacionamento de diferentes graus, segundo "os ambientes econômico e social nos quais estão imersas" (SHAPIRO, 1987, p. 62, tradução nossa). 0 conceito de confiança está, assim, relacionado à compreensão de expectativas numa estrutura geral de comportamento, inserido no sistema intraorganizacional de natureza institucional.

Esse ponto de vista contrapõe-se à idéia de confiança de caráter normativo (FUKUYAMA, 1996; PEYREFITTE, 
1999), que nasce no seio de uma comunidade de comportamento estável e cooperativo, baseando-se em normas compartilhadas por seus membros. Não se prevêem mudanças no padrão de confiança em ambientes de inovação, turbulentos e de rápida transformação.

No outro campo de estudo, encontra-se a confiança de caráter cognitivo, que pressupõe o compartilhamento de esquemas de interpretação e de sentidos, construídos por meio de interações com diferentes grupos sociais. Essa definição evita limitar a confiança a uma visão de cunho exclusivamente funcional ista, voltada à maximização de ganhos e à redução de perdas pessoais nas interações sociais. Foge do senso comum no qual se baseiam estudos que vinculam a confiança a compromissos legais ou à boa vontade das pessoas, sem o objetivo de contribuir para 0 entendimento das razões que estimulam ou desestimulam o relacionamento cooperativo sustentável a longo prazo (HARDY, PHILLIPS, LAW REN CE, 2000).

Como assinala Kramer (1999), concentrar a formação de confiança exclusivamente em expectativas de trocas recíprocas é uma mera versão de uma transação econômica repetida, o que é teoricamente frágil para justificar atitudes cooperativas.

Como esse exame ocorre no âmbito da gestão empresarial, as relações de confiança dentro das empresas são influenciadas por padrões sociais de comportamento no trabalho, longe, portanto, de posturas altruístas entre aqueles que protagonizam a vida social na empresa.

Nessa linha de análise, ensina Luhmann (1996), a confiança reduz a complexidade social e garante mais segurança para escolhas que se façam necessárias, na medida em que contribui para a superação da ausência de informações disponíveis sobre determinado tema e generaliza expectativas de comportamento. A confiança, assim, insere-se numa relação social na qual al guém investe recursos, autoridade ou responsabilidade na ação de outro para agir em seu nome, sob incertezas com relação ao resultado futuro (SHAPIRO, 1987).

Do ponto de vista da abrangência e da natureza do relacionamento, as análises encontradas na literatura mostram que a confiança possui características presentes em quase todas as linhas de pensamento: confiança implica investimento de risco e, portanto, expectativas de retorno oferecidas a uma pessoa para agir em favor de outra (COLEM AN , 1990). A introdução do fator risco no processo de estabelecimento da confiança ocorre nesse ponto, quando se percebe assimetria de tempo entre 0 investimento de recursos, quase sempre efetuado em momento anterior ao retorno da ação por parte do confiado.
Portanto, ao conceito de confiança, incorporam-se os seguintes pressupostos:

- A confiança reduz a sensação de complexidade do ambiente, na medida em que propõe ao indivíduo a garantia da realização de determinado compromisso que, isoladamente, ele não teria condições ou informação suficiente para fazer.

- A confiança se dá numa relação que envolve riscos, calculados ou não, de frustração.

A reflexão em torno da instalação de ambiente de confiança nas organizações tem como fim demonstrar al ternativas para lidar com a complexidade do contexto e reduzir a sensação de vulnerabilidade do homem na vida social, em especial nos relacionamentos interpessoais, favorecendo sua capacidade de ação e estimulan do a contribuição para um processo de trabal ho cooperativo.

Esse é um objetivo que se coaduna com o modelo organizacional e de gestão recomendado para a sociedade contemporânea. Ele não está sendo proposto para outros tipos de situação. Por exemplo, para estabelecer a rel ação entre o carcereiro e o prisioneiro em um sistema prisional, a característica confiança não se mostra essencial. Basta aplicar a força para privar o prisioneiro de sua liberdadee basta manter a ameaça da força para evitar que ele a reconquiste. As relações de trabal ho de um regime de servidão, tomando outro exemplo, não requerem confiança, mas um aparato repressivo que permita a aplicação da força, quando a dita relação sofrer a ameaça de desestabilização.

No trabalho que deu origem a este artigo, o conceito de confiança adotado refere-se a crenças e valores de probidade que permeiam as relações interpessoais em um ambiente organizacional. Essa crença fundamenta-se em que o comportamento das pessoas que 0 integram são aqueles baseados em princípios éticos e morais de correção em relação ao confiante. E que o sistema organizacional assegura essas ações e relações, e projeta objetivos e resultados levando-as em consideração.

\section{Vulnerabilidade humana em ambiente sem confiança}

Para melhor compreender a questão da vulnerabilidade humana nas organizações, são retomadas as reflexões filosóficas de Heidegger, originalmente publicadas na primeira metade do século passado, contidas nos dois volumes de Ser e tempo (1999).

Heidegger observa que todo homem é um ser. Como tal, o filósofo contesta a análise que procura oferecer um contorno, uma forma, um conceito para o ser, principalmente quando examinado sob uma perspectiva fragmentada - cor- 
po ou alma, racionalidade ou irracionalidade, dentre outras. Heidegger considera o ser como indefinível, por não o perceber como um objeto fixo e concluído que se pode apartar.

O ente, ao contrário, é determinável (branco, azul, grande, pequeno). Algo que se define num projeto sempre retomado, um modo de ser do homem, conforme assinala Pereira (2002), de poder-ser. Dessa forma, o ser encontra-se sempre em forma inacabada, construindo-se permanentemente a partir das experiências de sua existência. N ão é abstrato e indiferenciado e sim portador de história, competências, dificuldades e esperanças.

A existência é considerada a partir das possibilidades do ser, que pode encontrar-se ou perder-se. $\mathrm{Na}$ cultura de massas que caracteriza a sociedade contemporânea, as escol has são dadas como prontas e acabadas. Decidir-se pelo próprio caminho não é, portanto, tarefa fácil, bem como não o é permitir que as coisas se manifestem como de fato são, sem obedecer a categorias de consumo impostas pela sociedade.

A originalidade do pensamento heideggeriano desponta na noção de possibilidade, de revelação de algo novo (ABBAGNAN O, 2001). Em outras palavras, podese sempre ser amanhã algo diferente do que se é hoje, desde que se queira. Essa autonomia do ser humano em relação às suas escolhas e ao seu destino parece sinalizar para um cenário glorioso, no qual a perspectiva da liberdade individual é imensurável.

Contudo, quando a análise é remetida às condições concretas da existência humana, instaura-se um conflito interior em cada pessoa no momento em que ela percebe tais possibilidades, mas se reconhece insegura, vulnerável e, por conseqüência, ameaçada, precária e incompleta, ou seja, a escol ha do encontrar-se é repleta de desafios.

Como a existência humana é um conjunto de possibilidades de realizações, enão há certeza de nada, o homem se angustia ao descobrir-se lançado no mundo, sem ter escolhido isso, tendo de enfrentar o indeterminado sem saber 0 que lhe acontecerá.

A agravar ainda tal sensação, concorre o fato de o tempo traduzir o elemento que limita a vida, quando o homem se torna consciente de sua finitude pela perspectiva da morte, sem saber, contudo, o prazo que a vida Ihe reserva. Heidegger salienta que o pior a acontecer ao homem é fugir dessa realidade, ser indiferente à morte: "[...] a elaboração dessa indiferença 'superior' aliena a presença de seu poder-ser mais próprio" (1990, p. 37).

Para viver uma existência autêntica, em lugar de al iena$\mathrm{da}$, o homem deve se decidir por estar sempre retomando a si, consciente das possibilidades de seu ser no tempo, realizando projetos para antecipar o futuro.
Todavia, o mundo - enele a vida humana - não se revela por fatos e acontecimentos lineares e auto-explicáveis. 0 pensamento intrincado de Heidegger apresenta o mundo a partir de três naturezas distintas, ou três submundos coordenados, como prefere Inwood (2002, p. 120): 0 mundo do senso comum, ou seja, aquele em que objetos e sujeitos são simplesmente observáveis à nossa volta; 0 mundo pautado pela profundidade de interações entre as pessoas; e o mundo próprio, formado por valores, potenciais e realizações do ser.

O "mundo das interações" é a dimensão na qual a pesquisa procurou identificar as relações entre vulnerabilidade e confiança. Esse ambiente abrange interações desejáveis e não desejáveis, que traduzem empatia ou aversão com os que estão à volta. Tais interações se entrelaçam formando um referencial pleno de significado para a ação humana, cujo domínio não é simples, podendo angustiar e refrear iniciativas, inclusive paralisando as possibilidades de ação.

Quando a angústia priva o homem do significado das coisas, a vida transforma-se em algo fragmentado, pois ele desconhece as partes que a reúnem, bem como as iniciativas mais apropriadas para desafiá-la. N esse momento, o ser humano reconhece a grande vulnerabilidade que 0 ameaça e submete sua existência.

Reside nesse aspecto o efeito potencial de a confiança servir como mecanismo para reduzir a sensação de vulnerabilidade, avaliando o quanto de risco al guém está disposto a assumir. "A falta de confiança aumenta o temor" (ECHEVERRÍA, 2001,p. 97), cerceando a assunção de riscos para lidar com a complexidade do ambiente. Sem iniciativa, o homem não consegue superar seus desafios.

Forma-se um ciclo vicioso somente quebrado pelo estabelecimento de relacionamentos pautados pela confiança, que, em última análise, são o aspecto redutor da vulnerabilidade. Essa é a saída quando se constata 0 aumento da complexidade social produzida pelas interdependências cultural, comercial e financei ra no âmbito mundial. Da mesma forma, essa é a solução que pode dar conta da interdependência funcional no interior das empresas.

Um dos poucos consensos na teoria organizacional reside na advertência para reorientar o processo de trabal ho, tradicionalmente contido em relações de poder assimétricas, baseadas no medo e no controle, para outro mais aberto, que enfatize o trabal ho em equipe e redistribua o poder mediante seu compartilhamento (LAWLER III, 2000; DRUCKER, 2000; O'REILLY III, PFEFFER, 2000; SEN GE, 2001). No trabal ho em equipe, resgata-se a coesão grupal como atributo intrínseco ao fortalecimento da 
sociabilidade humana. 0 diálogo amplia a força da comunicação, ea troca de experiências extrai o mel hor da diversidade de conhecimentos e competências, resultando em melhor performance organizacional e podendo constituir diferencial de competitividade da organização.

Contribui para a disseminação da prática do diálogo a capacidade de as pessoas, no ambiente de trabal ho, acreditarem na possibilidade de mudanças e perceberem-se aptas para as concretizarem.

Apesar de Heidegger avançar na análise teórica do tema das possibilidades humanas e sua influência no sentido de requalificar a existência, ele não aborda especificamente o papel da confiança nesse processo. Luhmann (1996) assume essa iniciativa, por meio da premissa da existência de racionalidade na formação dos relacionamentos sociais, da qual deriva o pressuposto básico do conceito de confiança: mecanismo que reduz a complexidade e capacita pessoas a lidar com al tos níveis de incerteza da vida contemporânea. 0 autor assevera que, com a confiança, ações antes consideradas improváveis e sem atrativos passam a ser factíveis, diminuindo a sensação de risco que cerca a tomada de decisões.

A abordagem da confiança interpessoal por Luhmann reconhece que parte dos conflitos existentes no ambiente de trabal ho ocorre impulsionada por fatores que envolvem estruturas mais elaboradas e externas à organização. A conduta organizacional não estaria restrita, todavia, a ser a simples soma das ações individuais, em razão, segundo alguns autores (POWELL, DIMAGGIO, 1999), da natu reza não reflexiva e rotineira do modo de agir das pessoas no trabalho.

Admitir a influência do contexto não implica desconsiderar que muitos dos traços e qualidades inerentes aos relacionamentos advêm de interesses mútuos nascidos de interações no ambiente de trabal ho.

A concepção de possibilidade na vida humana, erigida por Hei degger, aliada à rel evância da confiança para a coexistência social, preconizada por Luhmann, oferece caminhos para a gestão da confiança interpessoal no trabalho. Mesmo quando se reconhece a interferência de aspectos ambientais incontroláveis, um dos principais efeitos da gestão da confiança interpessoal no trabal ho - e estímulo para a consolidação - é a incorporação da noção de previsibilidade na formação de relacionamentos.

A previsibilidade distingue-se como fundamento para o domínio básico da vulnerabilidade quando fornece segurança e bal iza regras de convivência. 0 termo "previsibilidade" é adotado neste estudo como solução al ternativa para o problema da incerteza social (YAM AGISHI, 2002). A previsibilidade aqui não se refere à dinâmica dos aconte- cimentos externos ao ser, distantes do domínio individual. Trabalha-se com a sensação de previsibilidade de natureza íntima, associada à expectativa de interações sociais que um sujeito tem em relação aos seus pares. A sensação se encontra na esfera privada e individual.

Essa percepção (de maior previsibilidade nas ações do outro) tem o condão de trazer maior tranqüilidade e meIhoria do bem-estar próprio, seja material ou psicológico. Quanto mais evidentes se tornam os compromissos entre as pessoas, mais previsíveis são as conseqüências das interações sociais e menos vulnerável é sua sensação em relação ao ambiente. Esse quadro concorre para a formação de um ciclo virtuoso (e valioso) para o enfrentamento de rupturas regulares provenientes do ambiente. "A confiança emerge gradual mente nas expectativas de continuidade, que se formam como princípios firmes com os quais podemos conduzir nossa vida cotidiana" (LUHMANN, 1996, p. 41, tradução nossa).

Enfrentar a complexidade social por meio da confiança é solução que aumenta a capacidade de o sistema funcionar em um entorno cada vez mais repleto de fatos e circunstâncias. Embora a confiança não seja o único meio de lidar com situações complexas, sua ausência causa, no limite, desarmonia, impasse e imobilismo.

Nas organizações empresariais, o grau de responsabilidades assumido pelas pessoas que se encontram nas categorias mais elevadas excede a capacidade individual de cumpri-las, principalmenteem razão da limitação de habilidades no processamento das informações (LUHMAN N, 1996). Quando se confia, al gumas opções onerosas são descartadas e certos perigos são neutralizados. É necessário confiar para al iviar tal complexidade, que isoladamente não se pode controlar. Dessa situação, podem nascer e ser cultivadas relações benéficas entre pares, superiores e subordinados.

Para a criação de um ambiente de interesses compartilhados e menores riscos associados à frustração da confiança, as relações devem ocorrer num campo de igualdade entre os atores. 0 caráter sustentável da confiança e o seu efeito redutor da complexidade têm como alicerce o fato de se considerar o interlocutor como igual, consciente de seu papel cooperativo para com os demais.

\section{METODOLOGIA DE TRABALHO}

N esta seção, descrevem-se os procedimentos e critérios adotados para a sel eção do método de pesquisa, para escolha dos sujeitos estudados e para a coleta dos dados utilizados nos trabal ho. 


\section{Seleção do método}

Os trabal hos acadêmicos que abordam o tema de confiança interpessoal caracterizam-se pela diversificação do uso de técnicas de natureza quantitativa e qual itativa, provavelmente em função da profusão de ângulos pelos quais se pode analisar o tema - econômico, psicológico e sociológico.

A natureza singular ea subjetividade inerentes ao fenômeno estudado justificam uma abordagem qual itativa para a análise da associação entre confiança e vulnerabilidade no trabalho. Em decorrência, assumiu-se que a investigação da vulnerabilidade humana no trabalho deveria: valorizar o contato direto do pesquisador com os sujeitos da pesquisa; permitir observação integral dos dados colhidos, com ênfase no processo e não exclusivamente nos resultados; e favorecer a descoberta de significados junto aos dados colhidos.

\section{Seleção dos sujeitos da pesquisa}

Foram realizadas entrevistas com um grupo de oi to profissionais com poder de decisão sobre funções empresariais, caracterizados como gerentes assalariados das organizações. Para estabelecer associações lógicas entre comportamentos e a sensação de vulnerabilidade no trabal ho, ou seja, um fenômeno singular condicionado por variáveis dificilmente replicáveis em outros ambientes, não se demanda uma amostra ampla, mas suficiente para apoiar o estudo dos principais temas que gravitam ao redor do problema de pesquisa.

A amostra considerou atributos de ordem pessoal (sexo, tempo de empresa e idade) e organizacional (porte, setor econômico e natureza jurídica da empresa). Parte dos entrevistados encontra-se trabal hando em multinacionais do setor de telecomunicação, farmacêutico, agroindustrial e de consultoria; parte em empresas de capital nacional, do ramo financeiro, de energia e educação. Todos os profissionais pertencem a organizações de médio e grande porte. Considerou-se apropriado focar a participação de gestores inseridos em setores de ponta da economia, mais diretamente afetados pelas turbulências e rupturas no mercado de trabalho.

A escolha desse grupo profissional se justifica em razão de recair indistintamente sobre tais sujeitos mudanças na perspectiva da ação gerencial nos últimos anos, em maior ou menor grau, em especial após a disseminação de técnicas de flexibilidade organizacional, a partir da década de 1970. 0 papel dos gestores desde então tem transitado de uma ênfase de controle tecnoburocrático, que obedece a rígido planejamento técnico de atividades, a uma "ação gerencial predominantemente dialógica" (TENÓRIO, 2000, p. 200).

\section{Coleta de dados}

As questões no processo de pesquisa orientaram-se por um roteiro que procurava estimular o diálogo espontâneo com o entrevistador. 0 questionário pode ser considerado como não-estruturado e aberto, 0 que indica a não-limitação de respostas, mas o fornecimento de “[...] uma estrutura de referência para as respostas" (COOPER, SCHINDLER, 2003, p. 278).

Dentro do repertório de técnicas qualitativas, as entrevistas em profundidade, de caráter individual, constituem-se como uma das ferramentas mais utilizadas para a obtenção de informações. Os temas abordados junto aos respondentes foram: a percepção do trabal ho num ambiente economicamente dinâmico, características do ambiente que causam sentimentos de insegurança, trabalho e confiança interpessoal, diferenças entre a percepção atual e a passada sobre confiança, atitudes e práticas que retratam a existência de confiança no trabal ho, desafios atuais para a coordenação de equipes, estímulos do ambiente que fortalecem e fragilizam a incorporação de confiança nos relacionamentos e influência do ambiente sobre a percepção de estabilidade profissional. Tais categorias foram concebidas de maneira a ser internamente consistentes, mas distintas umas das outras.

\section{ANÁLISE DOS DADOS}

A análise dos dados procurou unir a leitura dos signos ea experimentação, visando gerar evidências sobre o fenômeno estudado. Seguindo Bardin (2000), dentre as diferentes possibilidades de categorização na análise de conteúdos, a investigação dos temas ou análise temática, é rápida e eficaz para a compreensão das significações manifestas em discursos diretos. 0 processo envolveu a observação de regularidades no discurso dos respondentes, buscando-se expressões dentro de categorias quetivessem convergência interna e divergência externa.

\section{Ambiente de trabalho e confiança interpessoal}

As informações obtidas confirmam uma série de reflexões propostas por Bauman (2003) e Sennett (1998) sobre a prevalência de fatores econômicos em face dos sociais nas relações de trabalho, com ênfase orientada a relacionamentos previamente del imitados como de curta duração e rápida destruição. Relacionamentos, portanto, marcados pela idéia de substituição imediata. Quando convidados a refletir sobre o contexto do trabal ho, os entrevistados foram enfáticos em dar destaque à competitividade empresarial, traduzida por meio da busca quase incessante 
de maiores índices de lucratividade empresarial e do aumento da eficiência operacional.

A análise do material discursivo indica dois tipos de associações dicotômicas a respeito da influência exercida pelo contexto de trabal ho. Por um lado, percebe-se a associação de expressões positivas vinculando esse ambiente, economicamente dinâmico, revelado pela intensidade em ganhar do concorrente, em lidar com o imprevisto e com o surgimento de novas oportunidades, desafios e criatividade.

Por outro lado, associações de expressões negativas demonstram visão pessimista dos desdobramentos desse ambiente, principalmente relacionadas à pressão por resultados eà questão da ética. A abordagem do sentimento de insegurança está associada à verificação da existência (ou não) de percepção quanto a freqüentes rupturas nas relações de trabal ho e à intensificação do volume de trabal ho, com repercussões negativas na segurança financeira do profissional.

Embora certos respondentes tenham feito associação positiva com relação ao atual contexto de trabal ho, muitas vezes até entusiasmada, quando discorreram sobre um "sentimento de insegurança", percebe-se, de maneira mais evidente ou recolhida, a existência de al guma intranqüilidade, às vezes expressa em forma de descontentamento.

No conjunto das entrevistas, manifestou-se forte preocupação com a preservação do emprego e insatisfação com as relações de trabalho. Essa é uma tendência predominante na sociedade contemporânea, que reforça a da intranqüilidade gerada pela percepção de vulnerabilidade individual e de fragilidade das relações no ambiente de trabalho.

O sentimento em relação ao "mundo da competitividade/eficiência" causa certa ambigüidade: oportunidades de desenvolvimento pessoal e humano são bem acolhidas, riscos de perda de emprego e outras rupturas causam apreensão e insegurança. 0 ambiente que dá ênfase ao econômico em detrimento - e não em complemento - do social contribui para a formação de confiança restrita a trocas recíprocas e transacionais.

Quando solicitada a expressão que melhor poderia associar-se ao termo "trabal ho sob um ambiente de confiança", os entrevistados assinalaram que a instalação da confiança nas relações interpessoais "elimina traições", "não centraliza interesses", "propicia abertura", "fornece liberdade para sugestão", e "permite troca de informações". Aspectos associados à confiança institucional também estão presentes nas respostas, como "conhecimento (compartilhado) da estratégia da empresa", "planejamento de passos", "facilidade para a busca de objetivos", "integridade com efeitos para a produtividade", dentre outros.

As expressões utilizadas implicam uma visão reconfortante de confiança no trabalho: "zona de conforto", "colaboração", "tranqüilidade e transparência", "criatividade", "muito bom", "afetividade", "ética", "harmonia" e "espírito de equipe". Quando essas percepções são detalhadas, as descrições descortinam aspectos das relações entre pessoas e das pessoas com a organização que demonstram a mobilização para viabilizar a confiança no ambiente de trabal ho.

\section{Reação à confiança: mudanças na percepção atual em relação à do passado}

Os entrevistados foram também convidados a avaliar a percepção atual de confiança em rel ação ao passado, com o fim de averiguar, primeiro, o contexto atual da confiança e, depois, se as principais mudanças na relação de confiança se concentram no relacionamento entre as pessoas (relações mais determinadas) ou no relacionamento das pessoas com a empresa (relações menos determinadas), ao longo dos últimos anos.

A anál ise demonstra que existem referências em ambas as perspectivas, até de intensidade equilibrada. As manifestações não se centralizam em uma ou outra, o que permite inferir o caráter complementar de ambas como impacto à confiança na empresa.

Todos os respondentes destacaram mudanças entre a confiança atualmente existente e aquela que predominava nos relacionamentos do passado. Descontando-se uma tendência normal de as pessoas superestimarem situações passadas quando consideradas positivas, pode-se concluir que nessa comparação os entrevistados destacam aspectos positivos e negativos, os quais, ao interagir, adicionam complexidade ao ambiente organizacional. No que concerne aos aspectos positivos, ressal tam a "descentralização de atribuições", "maior disseminação de informações", "uso mais freqüente do diálogo" e "atitudes de mais respeito e tolerância" entre as pessoas. Mas as medidas de gestão que causam rupturas - demissões em larga escala, processos de fusões e aquisições gerenciados sem maiores cuidados com as pessoas e as relações - tendem a provocar dificuldades para estabelecer relacionamentos sólidos e duradouros.

É preciso levantar a possibilidade de os meios de comunicação modernos reduzirem o processo de formação de confiança. N ovas ferramentas de comunicação podem aperfeiçoar o controle das pessoas, de alguma maneira "formalizando o informal". Contatos que antes se bastavam pelo plano verbal, hoje dificilmente escapam da "obrigatoriedade" de registros por e-mails. A acrescentar, 
ainda, que, com tais facilidades, exige-se hoje dos interlocutores no trabal ho tal grau de eficiência e é tal a falta de tolerância ao erro, que se reduzem as possibilidades de disseminação da confiança no trabalho.

Os desafios sugeridos pelos entrevistados apontam questões do ponto de vista individual ("correr atrás de seus objetivos" e "tornar o trabal ho mais prazeroso"), mas, principalmente, do ponto de vista relacional ("conhecer melhor as pessoas", "gerir diversidade" e "aprimorar comunicação"). Todos os desafios para a gestão são acompanhados por impactos na confiança. Entrevistados enfatizaram o processo de comunicação interna ( "franqueza", "transparência") e a autonomia de ação e decisão como al avancadores da confiança no trabalho em equipe.

Busca-se, portanto, no discurso o estímulo à cooperação, ao diálogo, eventualmente até à maior tolerância; todavia, não se abre mão de estabelecer, como contrapartida, um clima de competição interpessoal e interorganizacional com o pretexto de assegurar que sejam cumpridos os objetivos organizacionais, e satisfeitas as expectativas de rentabilidade do negócio.

\section{0 crescimento da sensação de vulnerabilidade e influências no processo de gestão}

Este tópico sumariza o olhar sobre o tema da pesquisa, abordando fatores que hoje fortalecem ou fragilizam a incorporação da confiança nos relacionamentos entre as pessoas nas organizações.

Ratifica-se a premissa de que, de fato, a confiança, pela ênfase dada nas respostas, é fator que impulsiona a transformação da organização. De forma espontânea, os respondentes não só foram mais contundentes como também enfáticos na hora de apontar uma quantidade maior de fatores que fragilizam atualmente a confiança interpessoal nas organizações do que daqueles que a fortalecem. Essa situação corrobora a linha de raciocínio teórica adotada: 0 ambiente de intensa competitividade, sem gestão apropriada, corrói os relacionamentos no ambiente de trabalho, com repercussões no cl ima de confiança interpessoal estabelecido. Os comentários gravitam em torno de alguns fatores específicos, fundamentais para a instalação de ambiente de confiança interpessoal: compartilhamento de informações, consistência discurso/prática e delegação/autonomia de atividades. Se há mais aspectos que fragilizam a confiança em lugar de a fortalecerem, depreende-se um contexto de trabal ho fértil para fazer prosperar a sensação de vulnerabilidade analisada sob a óptica de Luhmann (1996).

0 questionamento, nas entrevistas, sobre vulnerabilidades percebidas no ambiente de trabal ho não se fez direta- mente, pois grande era a possibilidade de os respondentes negarem, simplesmente, qualquer percepção ou idéia de se sentirem vulneráveis.

0 primeiro passo, então, foi discutir os principais desafios para a coordenação de equipes, hoje, a fim de conhecer aspectos da gestão de pessoas que representem metas ou finalidades a serem al cançadas pelo grupo. Essa abordagem permite identificar se eventualmente há algum projeto comum para o aperfeiçoamento da prática de gestão e checar se esse projeto tem vinculação com 0 tema confiança interpessoal nas organizações.

A maioria dos respondentes associou os desafios à interação com os demais membros da equipe. Em resumo, foram pontuados aspectos como necessidade de melhor conhecimento das pessoas, desenvol vimento de ambiente de troca de idéias e informações, gestão da diversidade, estabelecimento de objetivos comuns, aperfeiçoamento da comunicação, aperfeiçoamento do relacionamento com a equipe e habilidades em lidar com pessoas cada vez mais qualificadas. Somente um dos respondentes enfatizou aspectos de cunho administrativo e não relacional: melhor gerenciamento do tempo e etapas de um projeto.

Verificou-se, ainda, se haveria barreiras interpondose entre o desejo e a efetiva superação desses desafios. Tais barreiras são a exteriorização de vulnerabilidades decorrentes da dinâmica do atual ambiente de trabal ho, sob a roupagem de aspectos que fragilizam a confiança interpessoal.

As manifestações mais diretamente associadas a verificar os aspectos representativos da percepção da vulnerabilidade dos gerentes pela ausência de confiança interpessoal são:

- Falta de compartilhamento de informações - "O gestor tem de usar critérios claros e transparentes [...] Se você tiver transparência, tiver justiça, com certeza haverá confiança dentro das equipes" (entrevistado de empresa multinacional farmacêutica).

- Não reconhecimento de habilidades - "Quando todas as pessoas são competentes em suas áreas, isso cria um estresse, um processo seletivo interno [...] Porque ao longo do tempo as pessoas sabem que são todos competentes e que todos merecem [...] E esse é um dos pontos que fragilizam a confiança" (entrevistado de empresa nacional da área financeira).

- Não conhecer expectativa em relação aos outros e viceversa - "O que fragiliza a confiança é aquele cara que derrete, [...] aquela pessoa polimórfica... que a cada hora está num formato. E isso é horrível!" (entrevistado de empresa da área de educação). "Você saber o que pode esperar e o que não pode esperar do outro é 
fundamental para existir confiança" (entrevistado de empresa multinacional de telecomunicações).

- Cooperação - "O que fragiliza a confiança é você ficar numa comparação muito grande. Você fica diminuindo as pessoas, ou você fica sempre botando o dedo na ferida, apontando os erros, esse tipo de coisa" (entrevistado de empresa multinacional de consultoria empresarial).

- Desconsiderar conseqüências pessoais em decisões administrativas - "Não é aquela confiança 'eu confio em você e você nunca vai me decepcionar', não. Essa confiança é muito mais no sentido de eu te entender exatamente como você é..." (entrevistado de empresa multinacional de telecomunicação).

- Inconsistência entre o discurso e a prática - "Você ser coerente com seu discurso [...] o discurso pode ser mudado, mas dê transparência" (entrevistado de empresa multinacional de agroindústria). "Mas o que aconteceé que, quando há essa incoerência, há uma cumplicidade de que ninguém denuncia [...] faz de conta que nada está acontecendo, o que afeta a confiança [...] 0 antídoto para a incoerência éreconhecer as (próprias) fraquezas" (entrevistado de empresa nacional de energia).

- Ausência de delegação e autonomia - "Por mais que vocêlute, por mais que vocêtenha argumentações, em algum momento se determina um prazo, um acordo, um cumpra-se [...] Então, eu vejo que muitas vezes, se a gente tem de implementar alguma coisa com poucas adaptações, isso fragiliza (a confiança)" (entrevistado de empresa multinacional farmacêutica).

0 referencial teórico permitiu vislumbrar o quanto é paradoxal o ambiente de trabal ho das organizações complexas. Pródigo em oferecer oportunidades de crescimento e desafios para as pessoas, simultaneamente acirra sua insegurança e vulnerabilidade. A mais freqüenteé provocada pela percepção da dificuldade de compartilhar com a empresa os planos de médio e longo prazo. Todas as circunstâncias de construção do seu destino, no sentido heideggeriano, parecem limitar-se ao momento, resignando-se com a incerteza do futuro.

\section{CONSIDERAÇÕES FINAIS}

0 enfraquecimento dos laços de confiança interpessoal contribui para o surgimento da sensação de vulnerabilidade decorrente da percepção de não-possibilidade (HEIDEGGER, 1999), que imobiliza o sujeito e dificulta a emergência de oportunidades de crescimento.
Observa-se, atualmente, que as possibilidades para a superação de desafios orientam-se por forças aparentemente contraditórias. De um lado, a sensação de angústia, fruto da incompreensão de alguns significados da realidade, arrefece 0 ímpeto para a ação. Por outro lado, a sensação de oportunidade de crescimento motiva a interação nos relacionamentos entre os indivíduos. Os entrevistados caracterizam essa sensação conflituosa quando identificam dissonâncias em seus ambientes de trabalho: possibilidades de crescimento pessoal (empregabilidade) e instabilidade profissional, cujo sentido não conseguem decifrar.

Embora a instalação de ambiente de confiança interpessoal não esgote a sensação de vulnerabilidade frente ao contexto, para os gerentes pesquisados, a existência de maior confiança no trabalho encontra-se associada à melhoria do relacionamento interpessoal com os demais membros das equipes. Da pesquisa, espontaneamente foram citadas diversas variáveis que comprovam o estudo realizado por Reina e Reina (1999) sobre variáveis que potencializam o estabelecimento de vínculos de confiança e que podem ser gerenciadas no ambiente de trabal ho Em síntese, o estudo aponta para a necessidade de gestão de fatores da confiança nas organizações, identificados ao longo da análise de dados, dentre os quais se destacam, pela ênfase eintensidade de manifestações dos respondentes, o reconhecimento de habilidades, a coerência entre discurso e prática (comunicação franca e transparente) e o conhecimento mútuo de expectativas entre os membros das equipes.

Há circunstâncias de natureza macroeconômica e psicológica - esta eminentemente pessoal e longe da esfera de atuação do gestor - que influenciam a formação de relações de confiança. Tais fatores não foram aqui abordados por representarem outras dimensões teóricas, mas podem refrear iniciativas gerenciais de melhoria da confiança interpessoal no ambiente de trabalho.

Como direcionadores para futuras pesquisas, sugerese a continuidade das investigações sobre a confiança interpessoal no ambiente de trabal ho, possivelmente a partir de uma abordagem quantitativa, com hipóteses previamente delineadas. Considera-se viável também a aval iação da existência de rel ações causais entre variáveis acerca da instalação de um ambiente de confiança, com base em aspectos abordados pelos respondentes. Além dessas análises, poderiam ser realizados testes de relações entre variáveis do ambiente externo (econômicos e sociais), da confiança interpessoal e da percepção de vulnerabilidades frente ao contexto de trabal ho. Sugerese considerar especificidades como natureza jurídica 
(pública ou privada), porte, faturamento, setor industrial, entre outros, além de análise mais meticulosa de correlação entre variáveis de confiança interpessoal.

Ressal ta-se o caráter exploratório do estudo e a impossibilidade de generalizações das análises e conclusões, em razão da natu reza da amostra entrevistada e do cunho introdutório da pesquisa sobre a associação entre confiança interpessoal e a sensação de vulnerabilidade no ambiente de trabalho.

\section{REFERÊNCIAS}

AAKER, D. A,; KUMAR, V.; DAY, G. S. Pesquisa de marketing. São Paulo: Atlas, 2001.

ABBAGnANO, N. História da filosofia. v. 12. Lisboa: Presença, 2001

BARDIN, L. Análise de conteúdo. Lisboa: Edições 70, 2000.

BAUMAN, Z. Sociedadelíquida. Folha de S. Paulo, São Paulo. 19.10.2003. Entrevista concedida a Maria Lúcia Garcia Pallares-Burke. Caderno Mais!

BURBACH, R. e outros. Globalization and its discontents: the rise of postmodern socialisms. Cambridge: Regional Studies, 1998.

COLEMAN, J. S. Foundations of social theory. Cambridge: The Belknap Press of Harvard University Press, 1990.

COOPER, D.; SCHINDLER, P. M étodos de pesquisa em administração. Porto Alegre: Bookman, 2003.

DAVIS, J. H.; SCHOORMAN, D. F.; MAYER, R. C.; TAN, H. H. The trusted general manager and business unit performance: empirical evidence of a competitive advantage. Strategic Management Journal, v. 21, n.5, p. 563-576, 2000.

DEPARTAMENTO INTERSINDICAL DE ESTATÍSTICA E ESTUDOS ECONÔMICOS - DIEESE. A situação do trabalho no Brasil. São Paulo: Dieese, 2001.

DIMAGGIO, P. Conclusion: the futures of business organization and paradoxes of change. In: DIMAGGIO, P. (Org). The twenty-first century firm: changing economic organization in international perspective. Princeton: Princeton University Press, 2001.

DRUCKER, P. F. O advento da nova organização. In: Harvard Business Review. Gestão do conhecimento. Rio de Janeiro: Campus, 2000.

ECHEVERRÍA, R. Empresa emergente: a confiança e os desafios da transformação. Brasília: Universal - UCB, 2001.
FREITAS, H.; JANISSEK, R. Análise léxica e análise de conteúdo: técnicas complementares, seqüenciais e recorrentes para exploração de dados qualitativos. Porto Alegre: Sphinx, Sagra Luzzatto, 2000.

FUKUYAMA, F. Confiança: as virtudes sociais e a criação da prosperidade. Rio de Janeiro: Rocco, 1996.

HARDY, C.; PHILLIPS, N.; LAW REN CE, T. Distinguishing trust and power in interorganizational relations: forms and façades of trust. In: LANE, C.; BACHMAN, R. (Ed). Trust within and between organizations: conceptual issues and empirical applications. New York: Oxford University Press., 2000 .

HEIDEGGER, M. Ser e tempo. Parte I. Petrópolis: Vozes, 1999.

HEIDEGGER, M. Ser e tempo. Parte II. Petrópolis: Vozes, 1990.

INSTITUTO BRASILEIRO DE GEOGRAFIA E ESTATÍSTICA - IBGE. Associativismo, representação de interesses e intermediação política. Disponível em: 〈http://www.ibge.gov.br>. Acesso em 20.11.2003.

INW O OD, M. Dicionário Heidegger. Rio de Janeiro: Jorge Zahar, 2002.

KRAMER, R. M. Trust and distrust in organizations: emerging perspectives, enduring questions. Annual Review of Psychology, v. 50, p.569-598, 1999.

KURZ, R. O colapso da modernização. Rio de Janeiro: Paz e Terra, 1992.

LAWLER III, E. E. From the ground up: six principles for building the new logic corporation. San Francisco: Jossey-Bass, 2000.

LUHMANN, N. Confianza. Barcelona: Anthropos; México: Universidad Iberoamericana; Santiago do Chile: Instituto de Sociologia. Pontificia Universidad Católica de Chile, 1996.

NUNES, B. Heidegger \& ser e tempo. Rio de Janeiro: Jorge Zahar, 2004.

DATAFO LHA. O PAÍS DOS DIREITOS DE PAPEL. Folha de S. Paulo, São Paulo, 24.03.2002. Caderno Especial.

O'REILLY III, C. A.; PFEFFER, J. Hidden Value: How great companies achieve extraordinary results with ordinary people. Boston: Harvard Business School Press, 2000.

PEREIRA, J. L. R. A fenomenologia heideggeriana em Ser e tempo. Revista Filovirtua. Disponível em: বhttp://geocites.yahoo.com.br>Acesso em 16.01.2003.

PEYREFITTE, A. A sociedade da confiança: ensaio sobre as origens e a natureza do desenvolvimento. Rio de Janeiro: Topbooks, 1999.

PFEFFER, J. Seven practices of successful organizations. California Management Review, v. 40, n. 2, p. 96-122, 1998. 
POWELL, W.; DIMAGGIO, P. El nuevo institucionalismo en el análisis organizacional. México, DF: Fondo de Cultura Económica, 1999.

REINA, D.; REINA, M. Trust and betrayal in the workplace: building effective relationships in your organization. San Francisco: Berrett-Kohler, 1999.

RODRIK, D. Por qué hay tanta inseguridad económica en América Latina? Revista de la CEPAL, n. 73, P 7-31, 2001. Disponível em: বhttp://www. eclac.cl>Acesso em 20.04.2003.

ROSSEAU, D. ; M. e outros. N ot so different after all: a cross-discipline view of trust. Academy of Management Review, v. 23, n. 3, p. 394-404, 1998.

SAMPSON, P. Qualitative research and motivation research. Amsterdam: Esomar, 1991.

SENGE, P. A quinta disciplina: arte e prática da organização que aprende. São Paulo: N ova Cultural e Best Seller, 2001.
SEN NETT, R. 0 declínio do homem público: as tiranias da intimidade. São Paulo: Companhia das Letras, 1988.

SHAPIRO, S. The social control of impersonal trust. American Journal of Sociology, v. 93, n. 3, p. 623-658, 1987.

SPINK, M. J.; LIMA, H. Rigor e visibilidade: a explicitação dos passos de interpretação. In: SPINK, M. J. (Org). Práticas discursivas e produção de sentidos no cotidiano: aproximações teóricas e metodológicas. São Paulo: Cortez, 2000.

TENÓRIO, F. G. Flexibilização organizacional: mito ou realidade. Rio de Janeiro: FGV, 2000.

YAMAGISHI, T. Cross-societal experimentation on trust: a comparison of the United States and Japan. In OSTROM, E.;WALKER , J. (Ed). Trust \& Reciprocity. New York: Russel Sage, 2002.

\title{
Artigo recebido em 27.01.2005. A provado em 31.01.2008.
}

\author{
Rosa Maria Fischer \\ Professora da Faculdade de Economia, Administração e Contabilidade, Universidade de São Paulo \\ Doutora em Ciência Política pela Faculdade de Ciências Sociais, Universidade de São Paulo \\ Interesses de pesquisa nas áreas de administração do terceiro setor, gestão de pessoas do terceiro \\ setor e sociologia das organizações \\ E-mail: rfischer@usp.br \\ Endereço: Av. Prof. Luciano Gual berto 908, FEA I, Sala C13, Butantã, São Paulo - SP, 05508900 \\ José G aspar Nayme Novelli \\ Professor dos cursos de Pós-graduação em Administração no Ibmec - Brasília \\ Doutor em Administração pela Faculdade de Economia, Administração e Contabilidade, \\ Universidade de São Paulo \\ Interesses de pesquisa nas áreas de estratégia, planejamento, gestão de pessoas, confiança e \\ consumo \\ E-mail: gnovelli@uol.com.br \\ Endereço: Quadra SQN 209, Bloco A, Ap. 105, Asa N orte, Brasília - DF, 70854010
}

